\title{
An Improved Theoretical Model of Cigarette Smoke Filtration across Mono-Segment Cellulose Acetate Filters *
}

\author{
by \\ Du Wen ${ }^{1}$, Wen Jianhui ${ }^{~}$, Peng Bing ${ }^{2}$, Zhang Xiaobin ${ }^{2}$, Xie Fuwei ${ }^{2}$, Liu Huimin ${ }^{2}$, and Zhong Kejun ${ }^{1}$ \\ ${ }^{1}$ Technology Center of China Tobacco Hunan Industrial Co., Ltd., Changsha 410007, China \\ ${ }^{2}$ Zhengzhou Tobacco Research Institute of CNTC, Zhengzhou 450001, China
}

\section{SUMMARY}

An improved theoretical model was presented to predict the filtration efficiency of cigarette filters. Filtration equations of single fibers considering the interference of neighboring fibers were applied in the model. Cellulose acetate fibers in cigarette filters were approximated as cylinders. The fiber size was adjusted by its size projected on the flow field. The solid fraction of fibers in cigarette filters was recalculated using the size of the virtual cylinders. The varying flow velocity during smoking was taken into account when calculating the filtration efficiency. The effective hydrodynamic particle diameter of cigarette smoke was estimated to be $0.44 \mu \mathrm{m}$ by the difference of filtration efficiencies under ISO and Health Canada Intense (HCI) smoking regimes. Filtration contributions due to diffusion, interception and inertial impaction were $62 \%, 32 \%$ and $6 \%$, respectively, at a flow velocity of $0.38 \mathrm{~m} / \mathrm{s}$ for particles of $0.44 \mu \mathrm{m}$ diameter. The effect of inertial impaction was insignificant but not negligible under ISO smoking regime. The measured and predicted efficiencies of two cigarette samples were compared and satisfactory agreement was obtained. [Beitr. Tabakforsch. Int. 26 (2015) 232-240]

\section{ZUSAMMENFASSUNG}

Es wurde ein verbessertes theoretisches Modell zur Vorhersage der Filtrationseffizienz von Zigarettenfiltern vorgestellt. In diesem Modell wurden Filtrationsgleichungen von Einzelfasern unter Berücksichtigung der Interferenz benachbarter Fasern angewendet. Celluloseacetatfasern in Zigarettenfiltern wurden als Zylinder modelliert. Die Fasergröße wurde entsprechend ihrer im Flussfeld projizierten Größe angepasst. Die solide Fraktion von Fasern in Zigarettenfiltern wurde mithilfe der Größe der virtuellen Zylinder neu berechnet. Die veränderliche Strömungsgeschwindigkeit beim Rauchen wurde bei der Berechnung der Filtrationseffizienz berücksichtigt. Der effektive hydrodynamische Partikeldurchmesser von Zigarettenrauch wurde anhand der Differenz von Filtrationseffizienzen nach den Rauchprotokollen der ISO und Health Canada Intense (HCI) auf 0,44 $\mu \mathrm{m}$ geschätzt. Filtrationsbeiträge aufgrund von Diffusion, Interzeption und trägheitsbedingter Ablagerung betrugen jeweils 62\%, $32 \%$ bzw. 6\% bei einer Strömungsgeschwindigkeit von $0,38 \mathrm{~m} / \mathrm{s}$ für Partikel mit 0,44 $\mu$ Durchmesser. Die Wirkung der trägheitsbedingten Ablagerung nach dem ISORauchprotokoll war unbedeutend, aber nicht vernachlässig-

*Received: $27^{\text {th }}$ July 2014 - accepted: $20^{\text {th }}$ February 2015 
bar. Die gemessenen und vorhergesagten Effizienzen von zwei Zigarettenproben wurden verglichen und eine zufriedenstellende Übereinstimmung festgestellt. [Beitr. Tabakforsch. Int. 26 (2015) 232-240]

\section{RESUME}

Un modèle théorique amélioré fut présenté en vue de prédire l'efficacité de filtration des filtres à cigarettes. Dans ce modèle, des équations de filtration pour les fibres simples furent utilisées qui tiennent compte de l'interférence des fibres adjacentes. Les fibres en acétate de cellulose contenues dans les filtres à cigarettes furent considérées comme des cylindres. La taille de la fibre fut ajustée selon sa taille projetée sur le champ de propagation. La fraction solide des fibres contenues dans les filtres à cigarettes fut recalculée en utilisant la taille des cylindres virtuels. Les variations de la vitesse de filtration lors de l'usage du tabac furent intégrées lors du calcul de l'efficacité de filtration. Le diamètre hydrodynamique effectif des particules de fumée de cigarette fut estimé à une valeur de $0,44 \mu \mathrm{m}$ au regard de la différence des efficacités de filtration selon les paramètres de fumage énoncés par le Health Canada Intense (HCI) et l'ISO. Les contributions à la filtration causées par la diffusion, l'interception et l'impact par inertie s'élevèrent à respectivement $62 \%, 32 \%$ et $6 \%$, pour une vitesse de propagation de $0,38 \mathrm{~m} / \mathrm{s}$ pour des particules de $0,44 \mu \mathrm{m}$ de diamètre. L'effet de l'impact par inertie fut insignifiant mais considéré comme non négligeable conformément aux paramètres de fumage de l'ISO. Les efficacités mesurées et prédites de deux échantillons de cigarettes furent comparées et une concordance satisfaisante fut obtenue. [Beitr. Tabakforsch. Int. 26 (2015) 232-240]

\section{INTRODUCTION}

Studies on cigarette smoke filtration have become abundant since the use of cigarette filters. Most studies are focused on empirical patterns of the filtration for various smoke components (1-4). There is also research on filtration theory of cigarette filters. KEITH established models for the prediction of pressure drop and filtration efficiency using HAPPEL solutions of the NAVIER-STOKES equations and LANGMUIR's equation (5-7). OVERTON found that at a velocity of $35 \mathrm{~cm} / \mathrm{s}$ the relative contributions to filtration by diffusion and interception were $40 \%, 60 \%$, respectively, while the contribution of inertial impaction was negligible (8). OVERTON's calculation was based on the different correlation of the three filtration mechanisms with flow velocity. There are three major difficulties in the theoretical modeling of smoke filtration. One of the difficulties is the interference of neighboring fibers. FUCHS and STECHKINA introduced KUWABARA-HAPPEL flow field using a cell model to take the effect of neighbor fibers into account in their study on fibrous aerosol filters (9). LEE and LIU established theoretical equations for filtration mechanisms of diffusion and interception using a boundary layer approach (10), which provides better results for fibrous filters. A second difficulty is that the orientation and shape of cigarette filter fibers are different from classic models.
The fibers in the filters are generally not perpendicular to the flow. The angle of fiber to flow direction ranges from $18^{\circ}$ to $49^{\circ}$ as a result of the crimping of fibers according to INAGAKI's study (11). The cross-section of a cellulose acetate fiber is usually Y-shaped. However, in the classic fiber filtration models, equations were derived for cylindrical fibers perpendicular to the flow field. This problem was usually solved by adjusting some parameters (7) to approximate the real situation but not by rebuilding the whole filtration equations. The third difficulty is the determination of the smoke particle size distribution. Particle size influences filtration efficiency significantly $(12,13)$. There are many studies on the particle size distribution of cigarette smoke. The mass median diameter of smoke particles obtained ranges from $0.2 \mu \mathrm{m}$ to $0.8 \mu \mathrm{m}$ (14-17). Because of these difficulties, most of the established models need some calibration coefficients determined by the measured filtration efficiencies and the filter properties $(1-6,8,11)$. KEITH established a totally theoretical filtration model (7). In his model, the effective fiber size was determined by the measured pressure drop and the pressure drop prediction equation. However, KEITH eliminated the particle size as a variable, which was only reasonable for identical cigarette smoke.

In this study, we presented an optimized theoretical model for the prediction of smoke filtration efficiency of cellulose acetate cigarette filters. The effect of neighboring fibers was taken into account by applying LEE and LIU's theoretical equations (10). A novel approximation approach was introduced to make the Y-shaped cellulose acetate fibers match the theoretical equations derived for cylindrical fibers. A new method for the estimation of the effective particle size of the cigarette smoke was developed utilizing the difference of the filtration efficiency of the filters under ISO and HCI smoking regimes. The varying flow velocity during smoking was taken into account when calculating the filtration efficiency to avoid its nonlinear influence. The model was validated by comparing the predictions to the measured filtration efficiencies of the filters of different length or different number of fibers. The theoretical model makes it possible to calculate the filtration efficiencies of the filters by filter variables such as length, solid fraction, section area, fiber size and flow parameters without any calibration.

If not indicated specially, all units in this paper are the base units or derived units of the International System of Units.

\section{EXPERIMENTAL}

\section{Cigarettes}

Two cigarette samples with conventional cellulose acetate filters were prepared. Their specifications are listed in Table 1.

\section{Smoke collection}

Cigarettes were smoked on a Cerulean SM450 (Cerulean, Milton Keynes, UK) smoking machine under both ISO (18) (35 $\mathrm{mL}$ puff volume, $2 \mathrm{~s}$ puff duration, one puff per min) and HCI (19) (55 mL puff volume, $2 \mathrm{~s}$ puff duration, one 
Table 1. Specifications of cigarette samples.

\begin{tabular}{|c|c|c|}
\hline Specification & Sample 1 & Sample 2 \\
\hline Tobacco rod length $(\mathrm{mm})$ & 56 & 59 \\
\hline Filter length (mm) & 28 & 25 \\
\hline Filter CA specification (denier) $^{a}$ & $3.0 / Y 32000$ & $3.0 / Y 35000$ \\
\hline Filter overwrap length (mm) & 35 & 33 \\
\hline Filter ventilation $(\%)$ & 0 & 0 \\
\hline Cigarette circumference (mm) & 24.2 & 24.2 \\
\hline Filter rod circumference $(\mathrm{mm})$ & 23.8 & 23.8 \\
\hline Cigarette pressure drop $(\mathrm{Pa})$ & 1100 & 1180 \\
\hline Blend style & flue-cured & flue-cured \\
\hline Weight of cigarette $(\mathrm{g})$ & 0.91 & 0.91 \\
\hline Basis weight of cigarette paper $\left(\mathrm{g} / \mathrm{m}^{2}\right)$ & 29 & 28 \\
\hline Cigarette paper permeability (CU) & 60 & 70 \\
\hline
\end{tabular}

${ }^{a}$ Denier is defined as the weight in grams of a single filament 9000 meters long. '3.0 / Y32000' means the denier of the single filament is 3.0, the filament is Y-shaped and the sum of the denier of all filaments in the filter is 32000 .

puff per $30 \mathrm{~s}$ ) smoking regimes. Total particulate matter from five cigarettes under ISO smoking and two cigarettes under HCI smoking was collected on 44-mm Cambridge filter pads.

\section{Method for the analysis of nicotine}

Nicotine was extracted with isopropanol from the Cambridge filter pad according to ISO 10315:2000 (20) and extracted from the filters with isopropanol (with $0.1 \%$ $\mathrm{NaOH}$ ) according to China standard YC/T 154-2001 (21). Analysis was carried out by GC (Agilent 6890, Agilent Technologies Co. Ltd., Santa Clara, USA) with a DB35MS glass capillary column and flame ionization detector, with detector temperature set at $280{ }^{\circ} \mathrm{C}$, a sample inlet temperature of $250^{\circ} \mathrm{C}$, a sample inlet of $1 \mu \mathrm{L}$, a split-flow ratio of 20:1, with Helium as carrier gas, a flow velocity of $1.5 \mathrm{~mL} / \mathrm{min}$, and with an oven temperature and duration of $200{ }^{\circ} \mathrm{C}$ and $12 \mathrm{~min}$.

\section{Determination of filtration efficiency}

The filtration efficiencies of filters $(E)$ were calculated using the following equation [1]:

$$
E=\frac{W_{1}}{W_{1}+W_{2}}
$$

Where $W_{1}$ represents the amount of component retained in filter, and $W_{2}$ represents the amount of component present in mainstream smoke after exiting the filter.

Nicotine retention efficiency was chosen to represent the filter filtration efficiency for sample 1 . Ten cigarettes were smoked for each measurement and three replicates were carried out for each sample. Nicotine is one of the typical constituents in smoke particles. More than $90 \%$ of nicotine can be found in the particulate phase of cigarette smoke (6). According to KEITH (7), the ratio of particle removal efficiency and nicotine removal efficiency of filters is close to 1 .
Beside the filtration efficiency of the whole filter, filtration efficiencies of shorter filters were obtained by analyzing nicotine contents in consecutive filter parts. The filters were cut transversely into two segments at different positions after smoking. Nicotine contents in both segments were determined. The sum of nicotine contents in the two segments was compared to the nicotine content retained in the whole filter to determine the nicotine loss during cutting. Half of the nicotine loss was added back to each segment. The retention efficiency of the segment connected with cigarette rod represented the filtration efficiency of a short filter for the same cigarette.

The weight gain of the filter was used to calculate the filter filtration efficiency for sample 2 . Twenty cigarettes were smoked. Then the filter parts of these cigarettes were cut off and weighed. Filter parts of another 20 cigarettes without smoking were also weighed. The difference of the two weights corresponds to the particulate matter retained by the filters.

\section{THEORY}

\section{Pattern of the smoke flow}

The flow pattern of smoke in the filters can be predicted by Reynolds number $(R e)$.

$$
R e=\frac{\rho v d_{f}}{\mu}
$$

Where:

$\rho \quad=$ Density of flow;

$v=$ Gas velocity;

$d_{f}=$ Fiber diameter;

$\mu=$ Viscosity of flow.

The porosity ratio of a cellulose acetate filter is about $90 \%$ (11). For the smoke exiting the filters at $0.38 \mathrm{~m} / \mathrm{s}$, the flow velocity inside the filters is about $0.42 \mathrm{~m} / \mathrm{s}(0.38 / 0.90)$. According to the above equation, the Reynolds number of an air flow velocity of $0.42 \mathrm{~m} / \mathrm{s}$ passing around a cylinder fiber of diameter $25 \mathrm{~mm}$ at $40{ }^{\circ} \mathrm{C}$ is 0.7 . The Reynolds number of the smoke flow is much less than the critical Reynolds number 50 (22), which indicates that the flow is laminar. Single fiber filtration equations in consideration of interference of the neighbor fibers (10) were utilized for the calculation of the contribution of diffusion and interception to smoke filtration efficiency. Filtration due to inertial impaction was calculated by YeH's equation (23).

\section{Diffusional deposition}

Diffusional deposition occurs for small particles undergoing Brownian motion in an aerosol. Figure 1 illustrates this effect. The small particles may move away from the flow lines, collide with the fiber, and then be captured. 


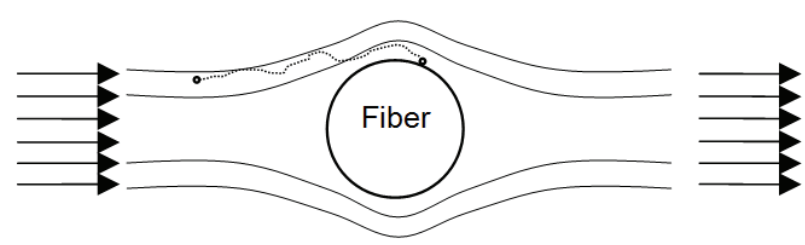

Figure 1. Illustration of diffusional deposition.

Considering the interference of neighboring fibers and using KUWABARA-HAPPEL flow field $(24,25)$, the filtration efficiency due to diffusion can be calculated by equation [3] (10).

$$
\eta_{D}=2.6\left(\frac{1-\alpha}{K u}\right)^{1 / 3} P e^{-2 / 3}
$$

Where:

$\eta_{D}=$ Single fiber filtration efficiency due to diffusion;

$\alpha=$ Solid fraction of filter;

$$
K u=-\frac{1}{2} \ln \alpha-\frac{3}{4}+\alpha-\frac{\alpha^{2}}{4}=
$$

Kuwabara hydrodynamic factor;

$$
P e=\frac{v d_{f}}{D}=\text { Peclet number; }
$$

$$
D=\frac{K_{B} T C_{u}}{3 \pi \mu d_{p}}
$$

$C_{u}=1+\frac{2 \lambda}{d_{p}}\left[1.257+0.4 e^{\left(-1.1 \frac{d_{p}}{2 \lambda}\right)}\right]$

$v \quad=$ Gas velocity;

$d_{f}=$ Fiber diameter;

$D$ = Particle diffusion coefficient;

$K_{B}=$ Boltzmann constant;

$T=$ Gas temperature;

$C_{u}=$ Cunningham correction factor;

$\mu=$ Viscosity of flow;

$d_{p}=$ Particle diameter;

$\lambda=$ Mean free path length of gas molecules.

\section{Direct interception}

Direct interception occurs for relatively large particles. In the flow passing by the fiber surface, particles with radius greater than the distance between the flow lines and the fiber surface may be captured by the fiber. Path 1 in Figure 2 is an illustration of interception.

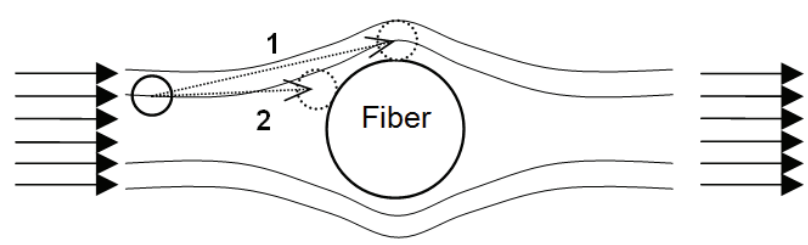

Figure 2. Illustration of (1) interception and (2) inertial impaction.

Filtration efficiency due to interception can be calculated by equation [4] (10).

$$
\eta_{R}=\frac{(1-\alpha) G^{2}}{K u(1+G)}
$$

Where:

$\eta_{R}=$ Single fiber filtration efficiency due to interception; $G=\frac{d_{p}}{d_{f}}=$ Ratio between particle diameter and fiber diameter.

\section{Inertial impaction}

Inertial impaction is likely to occur for heavy particles at relative high flow velocity. Path 2 in Figure 2 shows this effect. While the flow lines are curved near the fiber surface, particles with high kinetic energy tend to keep their original direction of movement and then impact onto the fiber. Filtration efficiency due to inertial impaction can be calculated by equation [5] (23).

$$
\eta_{I}=\frac{S t k \times J}{4 K u^{2}}
$$

Where:

$\eta_{I}=$ Single fiber filtration efficiency due to inertial impaction;

$S t k=\frac{\rho_{p} d_{p}^{2} C_{u} v}{18 \mu d_{f}}=$ Stokes number;

$J=\left(29.6-28 \alpha^{0.62}\right) \mathrm{G}^{2}-27.5 \mathrm{G}^{2.8}$

$\rho_{p}=$ Particle density.

\section{Filtration efficiency of cigarette filter}

Diffusion, interception and impaction work simultaneously during filtration. The combined single fiber efficiency can be calculated by the products of penetration ratio as equation [6].

$$
\eta_{S}=1-\left(1-\eta_{D}\right)\left(1-\eta_{R}\right)\left(1-\eta_{I}\right)
$$

The overall filtration efficiency of a filter $\eta_{0}$ can be calculated from the single fiber efficiency by equation [7] (13). 


$$
\eta_{0}=1-e^{-\frac{4 \eta_{S} \alpha L}{(1-\alpha) \pi d_{f}}}
$$

Where:

$L \quad=$ Length of the cigarette filter.

\section{RESULTS AND DISCUSSION}

\section{Approximation of fiber parameters}

The filter fibers of sample 1 and sample 2 are not cylinders but Y-shaped. KEITH used the outline size (' $R$ ' as shown in Figure 3 ) of the fiber to approximate the classic filtration theories $(6,7)$. This approximation was reasonable for fibers similar to a cylinder but not suitable for Y-shaped fibers. According to the single fiber filtration theories, interception and impaction are proportional to the size projection of the fiber onto the flow field. So the average of the projection size as shown in Figure 3 is chosen to calculate the effective diameter $d_{\mathrm{f}}$ of a filter fiber.

$$
d_{\mathrm{f}}=\int_{\pi / 6}^{\pi / 3}(R \cos \theta+R \cos (\pi / 3-\theta)) d \theta /(\pi / 6)
$$

The solid fraction $\alpha$ of the filter is calculated using the fiber diameter $d_{\mathrm{f}}$

$$
\alpha=\frac{\sum S_{\text {fiber }}}{S_{\text {filter }}}(1+C)=\frac{D_{t} \pi d_{f}^{2}(1+C)}{4 D_{S} S_{\text {filter }}}
$$

Where:

$D_{\mathrm{t}} \quad=$ Total denier of filter;

$D_{\mathrm{s}} \quad=$ Denier per single fiber;

$C$ = Crimping ratio of fibers;

$S_{\text {fiber }}=$ Cross-sectional area of fiber;

$S_{\text {filter }}=$ Cross-sectional area of filter rod.

For the $3.0 / \mathrm{Y} 32000$ filter of sample $1, R$ is $15 \mu \mathrm{m}, C$ is $17 \%, S_{\text {filter }}$ is $45.1 \mathrm{~mm}^{2}, d_{\mathrm{f}}$ is $25.1 \mu \mathrm{m}$ and $\alpha$ is 0.138 . For the $3.0 / Y 35000$ filter of sample $2, \alpha$ is 0.150 , while $d_{\mathrm{f}}$ is again $25.1 \mu \mathrm{m}$.

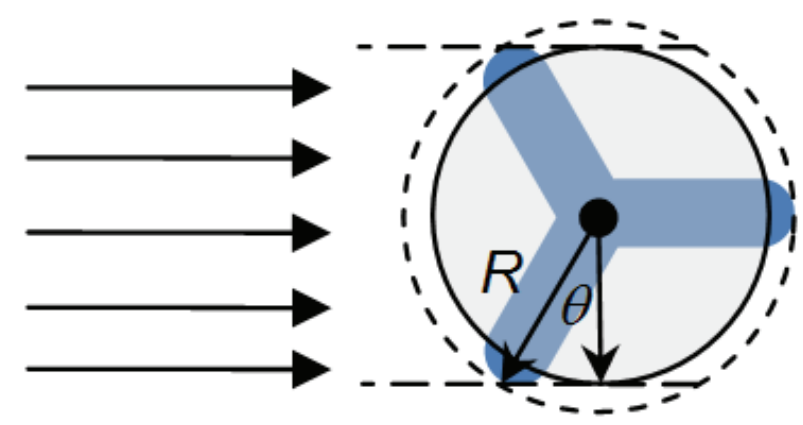

Figure 3. Approximation of the shape and diameter of the fiber.
The approach for diffusion is relatively complicated because both, deposition area and deposition pathway, have effects on diffusional deposition. The circumference of the cylinder as approximated above is about $88 \%$ $\left(25.1^{*} \pi /\left(15^{*} 6\right)\right)$ of that of the outline of the Y-shaped section. Compared with the actual deposition conditions around the Y-shaped fiber, the deposition area is smaller and the motion distance of the particles from the flow onto the fiber surface is shorter for the approximated cylinder. The smaller area decreases the deposition efficiency. And the short motion distance enhances the deposition efficiency. The two effects counteract in a certain extent.

\section{Influence of flow velocity on filtration efficiency}

High flow velocity promotes impaction effects and reduces diffusion effects. Interception is not affected by flow velocity. Figure 4 presents the influence of flow velocity on diffusion, interception, impaction and the combined filtration efficiency for $0.44 \mu \mathrm{m}$ particles. Under the conventional average flow velocity during puffing of $0.38 \mathrm{~m} / \mathrm{s}$ for ISO smoking and $0.60 \mathrm{~m} / \mathrm{s}$ for HCI smoking, diffusion is the dominant filtration mechanism. Between $1.1 \mathrm{~m} / \mathrm{s}$ and $1.9 \mathrm{~m} / \mathrm{s}$, interception is the most effective mechanism. Impaction becomes the most effective above $1.9 \mathrm{~m} / \mathrm{s}$. The puff volumes corresponding to the average velocities of $1.1 \mathrm{~m} / \mathrm{s}$ and $1.9 \mathrm{~m} / \mathrm{s}$ are $99 \mathrm{~mL}$ and $171 \mathrm{~mL}$, respectively.

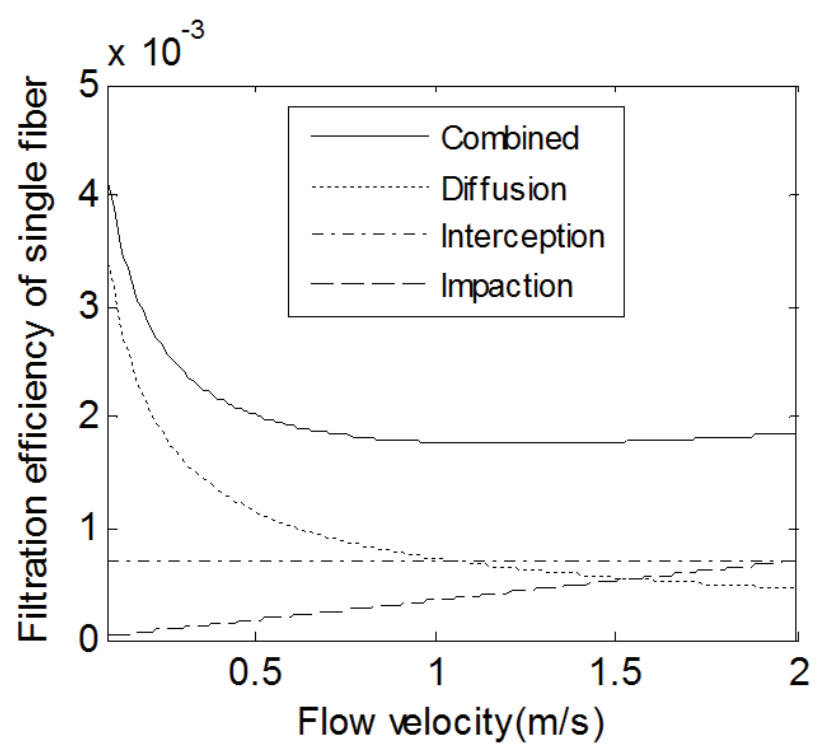

Figure 4. Influence of flow velocity on filtration efficiencies.

A notable change of the combined efficiency can be seen below $0.6 \mathrm{~m} / \mathrm{s}$ in Figure 5. The change of the flow velocity during smoking should be taken into account for the calculation of filter filtration efficiency because the average flow velocity cannot represent such nonlinear changes. The filtration efficiency of a cigarette filter with dynamic flow adjustment can be calculated by equation [10]. 


$$
\begin{gathered}
E=1-\int_{0}^{2} q(t)\left(1-\eta_{0}(t)\right) d t \\
q(t)=\frac{\pi}{4} \sin \left(\frac{\pi}{2} t\right)
\end{gathered}
$$

Where:

$q(t)=$ Volumetric flow at time $t$ relative to total puff volume; $\eta_{0}(t)=$ Filtration efficiency at time $t$ calculated by equation [7].

Figure 5 shows the change of filtration efficiencies for particles of various sizes during puffing under ISO smoking regime. For the filters of sample 1, the relative systematic deviation of the calculated filtration efficiencies with and without dynamic flow adjustment for the particles of $0.2 \mu \mathrm{m}, 0.4 \mu \mathrm{m}$ and $0.6 \mu \mathrm{m}$ is $6 \%, 3 \%$ and $1 \%$, respectively.

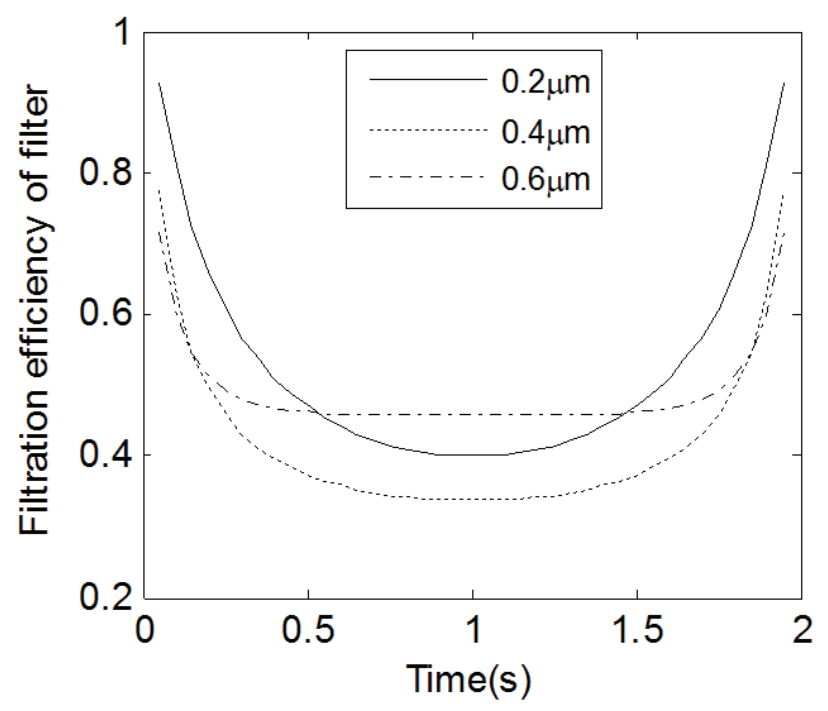

Figure 5. Filtration efficiencies of filters for particles of $0.2 \mu \mathrm{m}$, $0.4 \mu \mathrm{m}$ and $0.6 \mu \mathrm{m}$ during puffing under ISO smoking regime.

Estimation of effective hydrodynamic diameter of smoke particles

The filtration efficiencies for particles of various diameters under both ISO and HCI smoking regimes are calculated by equation [10]. The results are presented in Figure 6. For particles larger than $0.58 \mu \mathrm{m}$, the higher flow velocity under HCI smoking makes the filtration more effective than under ISO smoking. On the contrary, the filtration for particles smaller than $0.58 \mu \mathrm{m}$ under HCI smoking is less effective. This property of the cigarette filter was utilized to estimate the effective hydrodynamic diameter of smoke particles. In Figure 7, the difference of filtration efficiencies under HCI and ISO smoking versus particle diameter was plotted. The measured difference is $0.359-0.391=-0.032$ referring to the data in Table 2. So the effective hydrodynamic diameter of smoke particles was estimated to be $0.44 \mu \mathrm{m}$. Another corresponding size $0.06 \mu \mathrm{m}$ is not reasonable because the filtration efficiency is extremely high at this point. This value represents the particle size of the mass distribution center rather than the geometric distribution center of the smoke particles. This estimation assumes that the particle sizes are not affected by the smoking intensity.

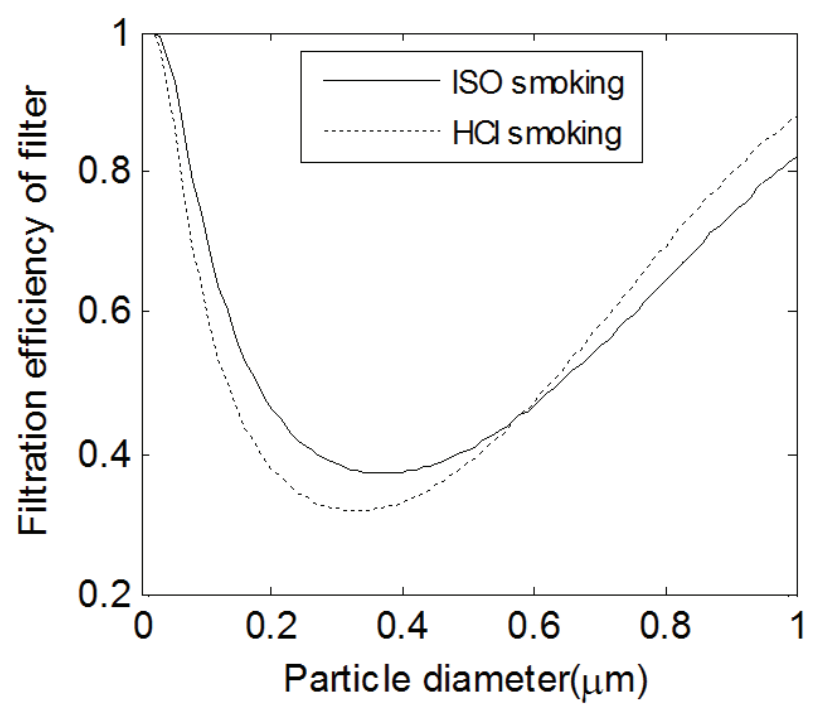

Figure 6. Filter filtration efficiencies under ISO smoking and $\mathrm{HCl}$ smoking.

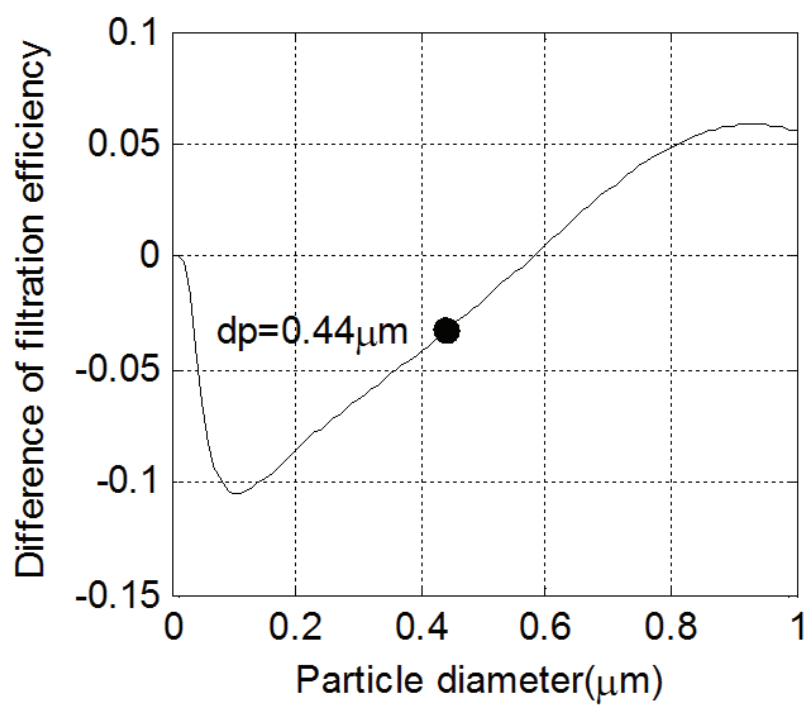

Figure 7. Relationship of efficiency difference and effective particle diameter.

Filtration contributions due to diffusion, interception and impaction

At a flow velocity of $0.38 \mathrm{~m} / \mathrm{s}$, single fiber filtration efficiencies by diffusion, interception and impaction were calculated separately by equations [3-5]. The combined filtration efficiency was calculated by equation [6]. The results are shown in Figure 8. As the particle size increases, the contribution of diffusion declines, and interception and impaction become more important. Diffusion is the major effect for particles smaller than $0.57 \mu \mathrm{m}$. Interception and diffusion are the major effects in the range from $0.57 \mu \mathrm{m}$ to $0.73 \mu \mathrm{m}$. Diffusion becomes the smallest effect above 0.73 $\mathrm{mm}$. The combined filtration efficiency curve indicates that the minimum efficiency occurs for particles with a diameter of $0.4 \mu \mathrm{m}$. The filtration efficiency is the lowest and changes slightly in the particle diameter range from $0.3 \mu \mathrm{m}$ to $0.5 \mu \mathrm{m}$. For particles of $0.44 \mu \mathrm{m}$ diameter, the filtration contributions due to diffusion, interception and impaction 
Table 2. Filter filtration efficiencies of sample 1.

\begin{tabular}{|c|c|c|c|c|c|c|c|c|}
\hline \multicolumn{9}{|c|}{ Nicotine content measured (mg/cig) } \\
\hline & \multicolumn{4}{|c|}{ Under ISO smoking regime } & \multicolumn{4}{|c|}{ Under $\mathrm{HCl}$ smoking regime } \\
\hline Measurements & 1 & 2 & 3 & Mean & 1 & 2 & 3 & Mean \\
\hline Mainstream yield & 1.15 & 1.16 & 1.19 & & 2.31 & 2.26 & 2.44 & \\
\hline Filter retention & 0.74 & 0.74 & 0.77 & & 1.31 & 1.26 & 1.36 & \\
\hline Total release & 1.89 & 1.90 & 1.96 & & 3.62 & 3.52 & 3.80 & \\
\hline Filtration efficiency & $39.2 \%$ & $38.9 \%$ & $39.3 \%$ & $39.1 \%$ & $36.2 \%$ & $35.8 \%$ & $35.8 \%$ & $35.9 \%$ \\
\hline
\end{tabular}

are $62 \%, 32 \%$ and $6 \%$ respectively. OVERTON found that at a velocity of $35 \mathrm{~cm} / \mathrm{s}$ the relative contributions to filtration by diffusion and interception were $40 \%, 60 \%$, respectively, while the contribution of inertial impaction was negligible (8). OVERTON's calculation depended on the determination of the velocity of maximum penetration $\left(\mathrm{v}_{\mathrm{p}}\right)$. But the value of $v_{p}$ was not measured but estimated by a different filtration model.

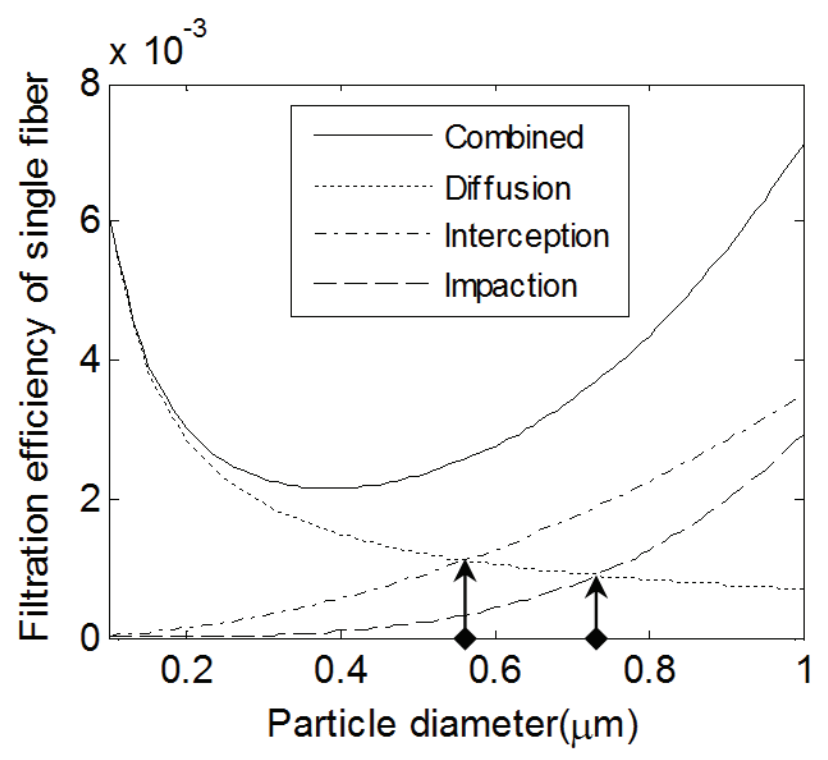

Figure 8. Filtration contributions due to diffusion, interception and impaction.

\section{Model validation}

Measured and predicted filtration efficiencies under ISO and HCI smoking regimes of sample 1 with filter lengths varying from $28 \mathrm{~mm}$ to $5.6 \mathrm{~mm}$ are listed in tables 3 and 4 and shown in Figures 9 and 10. The root mean square errors between prediction and measurement were 0.017 and 0.014 for ISO and HCI smoking, respectively.

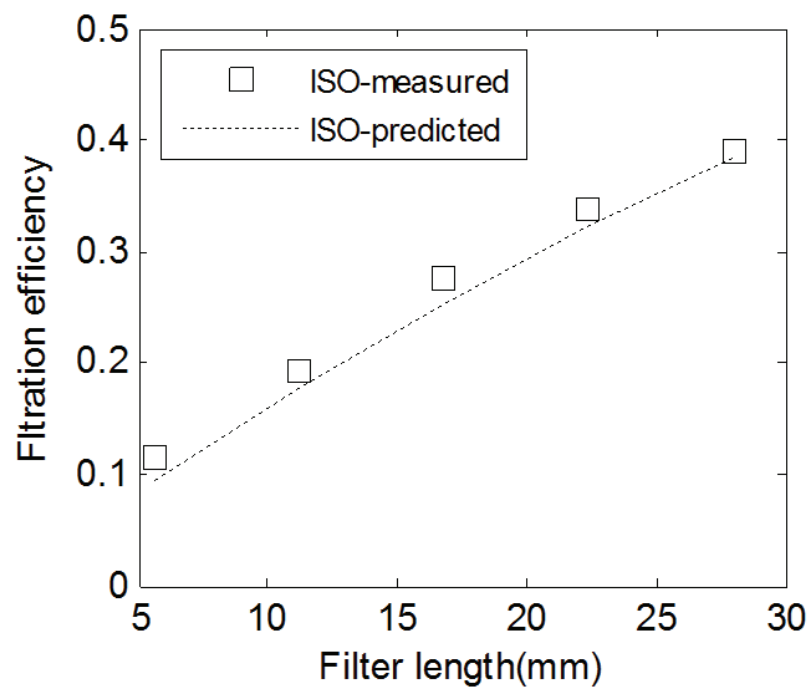

Figure 9. Predicted and measured filtration efficiencies under ISO smoking regime.

Table 3. Filtration efficiencies of sample 1 having different filter length under ISO smoking.

\begin{tabular}{c|ccc|ccc}
\hline Filter length & \multicolumn{7}{c|}{$\begin{array}{c}\text { Nicotine retained in filter } \\
\text { (mg/cig) }\end{array}$} & $\begin{array}{c}\text { Measured } \\
\text { efficiency }\end{array}$ & $\begin{array}{c}\text { Predicted } \\
\text { efficiency }\end{array}$ \\
\hline & 1 & 2 & 3 & Mean & & \\
$28.0 \mathrm{~mm}$ & 0.74 & 0.74 & 0.77 & 0.75 & $39.1 \%$ & $38.4 \%$ \\
$22.4 \mathrm{~mm}$ & 0.65 & 0.66 & 0.63 & 0.65 & $33.8 \%$ & $32.2 \%$ \\
$16.8 \mathrm{~mm}$ & 0.54 & 0.53 & 0.53 & 0.53 & $27.6 \%$ & $25.3 \%$ \\
$11.2 \mathrm{~mm}$ & 0.40 & 0.37 & 0.36 & 0.37 & $19.3 \%$ & $17.8 \%$ \\
$5.6 \mathrm{~mm}$ & 0.22 & 0.21 & 0.23 & 0.22 & $11.5 \%$ & $9.4 \%$ \\
\hline
\end{tabular}


Table 4. Filtration efficiencies of sample 1 having different filter length under $\mathrm{HCl}$ smoking.

\begin{tabular}{|c|c|c|c|c|c|c|}
\hline \multirow[t]{2}{*}{ Filter length } & \multicolumn{4}{|c|}{$\begin{array}{l}\text { Nicotine retained in filter } \\
\text { (mg/cig) }\end{array}$} & \multirow[t]{2}{*}{$\begin{array}{l}\text { Measured } \\
\text { efficiency }\end{array}$} & \multirow[t]{2}{*}{$\begin{array}{l}\text { Predicted } \\
\text { efficiency }\end{array}$} \\
\hline & 1 & 2 & 3 & Mean & & \\
\hline $28.0 \mathrm{~mm}$ & 1.31 & 1.26 & 1.36 & 1.31 & $35.9 \%$ & $35.2 \%$ \\
\hline $22.4 \mathrm{~mm}$ & 1.12 & 1.13 & 1.10 & 1.12 & $30.7 \%$ & $29.4 \%$ \\
\hline $16.8 \mathrm{~mm}$ & 0.89 & 0.88 & 0.89 & 0.89 & $24.4 \%$ & $23.0 \%$ \\
\hline $11.2 \mathrm{~mm}$ & 0.64 & 0.65 & 0.67 & 0.65 & $17.8 \%$ & $16.0 \%$ \\
\hline $5.6 \mathrm{~mm}$ & 0.36 & 0.37 & 0.37 & 0.37 & $10.1 \%$ & $8.4 \%$ \\
\hline
\end{tabular}

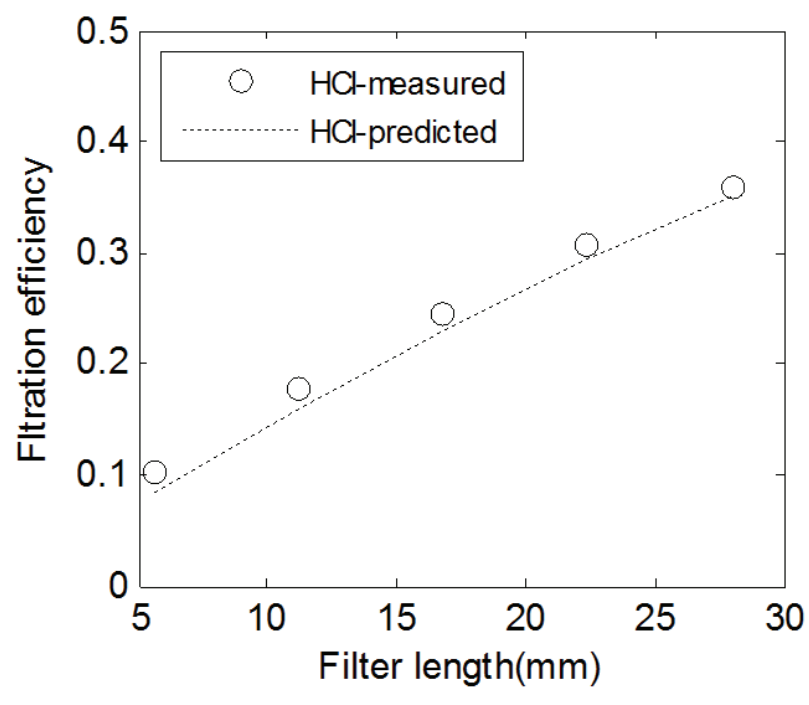

Figure 10. Predicted and measured filtration efficiencies under $\mathrm{HCl}$ smoking regime.

This result indicates that the theoretical calculation agrees well with real filtration. The filter of sample 2 was shorter but had more fibers compared to sample 1 . The shorter length reduces filtration efficiency. The higher solid fraction enhances filtration. The overall efficiencies both measured and predicted are listed in Table 5. The release from the filters is neglected. The relative prediction errors are less than $7.5 \%$.

Table 5. Predicted and measured filtration efficiencies of sample 2.

\begin{tabular}{lcc}
\hline \multicolumn{3}{c}{ Filtration efficiency (calculated by weight gain) } \\
\hline & ISO smoking & $\mathrm{HCl}$ smoking \\
Measured & $43.0 \%$ & $38.9 \%$ \\
Predicted & $39.8 \%$ & $36.8 \%$ \\
Relative error & $7.4 \%$ & $5.4 \%$ \\
\hline
\end{tabular}

\section{CONCLUSIONS}

An optimized theoretical model was presented to predict the smoke filtration efficiency of cigarette filters. Fibers in cigarette filters were approximated as cylinders with adjusted size and volume. The varying flow velocity during smoking was taken into account when calculating the filtration efficiency. The effective hydrodynamic particle size of the cigarette smoke was determined by the difference of filtration efficiencies under two smoking regimes. The estimated particle diameter was $0.44 \mu \mathrm{m}$. According to the calculation, filtration contributions due to diffusion, interception and inertial impaction were $62 \%$, $32 \%$ and $6 \%$, respectively, at flow velocity $0.38 \mathrm{~m} / \mathrm{s}$ for particles of $0.44 \mu \mathrm{m}$ diameter. The effect of inertial impaction was insignificant but not negligible for conventional flow velocities during puffing. The model was validated by comparing the measured and predicted efficiencies of two cigarette samples. The result indicates that the model based on the theoretical filtration equations simulates the real filtration well.

\section{REFERENCES}

1. Kao, J.: Practical Modeling of Filter Filtration Efficiency; Beitr. Tabakforsch. Int. 14 (1990) 341-352.

2. Dwyer, R.W. and S.G. Abel: The Efficiencies of Cellulose Acetate Filters; Beitr. Tabakforsch. Int. 13 (1986) 243-253.

3. Shepperd, C.J., F.K. St.Charles, M. Lien, and M. Dixon: Validation of Methods for Determining Consumer Smoked Cigarette Yields from Cigarette Filter Analysis; Beitr. Tabakforsch. Int. 22 (2006) 176-184.

4. Keith, C. H. and J.C. Denick: Cigarette Filter Efficiency as Measured With a Homogeneous Solid Aerosol; Tob. Sci. 9 (1965) 116-120.

5. Keith, C.H.: Pressure Drop - Flow Relationships in Cigarette Filter Rods and Tobacco Columns; Beitr. Tabakforsch. Int. 11 (1982) 115-121.

6. Keith, C.H.: Experimental and Theoretical Aspects of Cigarette Smoke Filtration; American Chemical Society Symposium Series 17 (1975) 79-90.

7. Keith, C. H.: Physical Mechanisms of Smoke Filtration; Rec. Adv. Tob. Sci. 4 (1978) 25-45.

8. Overton, R.: Filtration of Cigarette Smoke: Relative Contributions of Inertial Impaction, Diffusional Deposition, and Direct Interception; Beitr. Tabakforsch. Int. 7 (1973) 117-120.

9. Fuchs, N.A. and I.B. Stechkina: A Note on the Theory of Fibrous Aerosol Filters; Ann. Occup. Hyg. 6 (1963) 27-30.

10. Lee, K.W. and B.Y.H. Liu: Theoretical Study of Aerosol Filtration by Fibrous Filters; Aerosol Sci. Tech. 1 (1982) 147-161. 
11. Inagaki. W., N. Namiki, and Y. Otani: Influences of Fiber Crimp and Cross-sectional Shape on Particle Collection Performance of Cigarette Filter; J. Aerosol Res. 18 (2003) 278-286.

12. Keith, C.H. and J.C. Denick: Cigarette Filter Efficiency as Measured With a Homogeneous Solid Aerosol; Tob. Sci. 9 (1965) 116-120.

13. Lee, K.W. and B.Y.H. Liu: On the Minimum Efficiency and the Most Penetrating Particle Size for Fibrous Filters; J. Air Pollut. Control Assoc. 30 (1980) 377-381.

14. Keith, C.H.: Particle Size Studies on Tobacco Smoke; Beitr. Tabakforsch. Int. 11 (1982) 123-131.

15. Adam, T., J. McAughey, C. McGrath, C. Mocker, and R. Zimmermann: Simultaneous Online Size and Chemical Analysis of Gas Phase and Particulate Phase of Cigarette Mainstream Smoke; Anal. Bioanal. Chem. 394 (2009) 1193-1203.

16. Hinds, W.C.: Size Characteristics of Cigarette Smoke; Am. Ind. Hyg. Assoc. J. 39 (1978) 48-54.

17. Morie, G.P. and M.S. Baggett: Observations on the Distribution of Certain Tobacco Smoke Components with Respect to Particle Size; Beitr. Tabakforsch. Int. 9 (1977) 72-78.

18. International Organization for Standardization (ISO): International Standard ISO 3308:2009. Routine Analytical Cigarette-Smoking Machine - Definitions and Standard Conditions; ISO, Geneva, Switzerland 2009.

19. Health Canada: Official Method T-115 Determination of "Tar", Nicotine and Carbon Monoxide in Mainstream Tobacco Smoke; Health Canada, Ottawa, Canada, 1999.

20. International Organization for Standardization (ISO): International Standard ISO 10315:2000. Cigarettes -
Determination of Nicotine in Smoke Condensates Gas Chromatographic Method; International Organization for Standardization, Geneva, Switzerland, Second Edition, 2000.

21. China State Bureau of Quality and Technical Supervision (CSBQTS): YC/T 154-2001. Cigarettes Determination of Nicotine in Cigarette Filters Gas-Chromatographic Method; CSBQZ, Bejing, 2001.

22. Ding, Y. and M. Kawahara: Three Dimensional Linear Stability Analysis of Incompressible Viscous Flows Using the Finite Element Method; Int. J. Numer. Meth. Fluids. 31(1999) 451-479.

23. Yeh, H.C. and B.Y.H. Liu: Aerosol Filtration by Fibrous Filters-I. Theoretical; J. Aerosol Sci. 5 (1974) 191-217.

24. Kuwabara, S.: The Forces Experienced by Randomly Distributed Parallel Circular Cylinders or Spheres in a Viscous Flow at Small Reynolds Numbers; J. Phys. Soc. Jpn. 14(1959) 527-532.

25. Happel, J.: Viscous Flow Relative to Arrays of Cylinders; J. Am. Inst. Chem. Eng. 5 (1959) 174-179.

Corresponding author:

Du Wen

Technology Center

of China Tobacco Hunan Industrial Co., Ltd.

Changsha 410007

China

E-mail:duwen@hnu.edu.cn 